\title{
Biochemical effect of aqueous extract of Zingiberofficinale on hyperlipidemic rats
}

\author{
Nabil Taha, Mahdy Korshom, Abdel-WahabMandour, Mohamed Lebda* and AmanyKhaleil
}

Alexandria University, Department of Biochemistry, Faculty of Veterinary Medicine, P.O 22758 Edfina, Egypt

\begin{tabular}{l}
\hline ARTICLE INFO \\
$\begin{array}{l}\text { Key words: Ginger, testosterone, } \\
\text { thyroid hormone, troponin, } \\
\text { cholesterol }\end{array}$
\end{tabular}
cholesterol

\begin{abstract}
Objectives: The present study was performed to investigate the effect of aqueous extract of ginger on hypercholesterolemic rats.Methods: A total forty male rats were randomly divided into four groups (10 rats/ each). Control rats were fed basal ration and water ad libitum, hyperlipidemic rats were administeredTriton WR-1339 at dose of $250 \mathrm{mg}$ i.p/kg b.wt (three times/week), ginger-treated rats were fed orally on ginger aqueous extract at dose of $400 \mathrm{mg} / \mathrm{kg} \mathrm{b.wt}$, and the forth groupwhere the rats treated with aqueous extract of ginger before induction of hyperlipidemia for three weeks. Blood sample were collected from all groups and serum was separated for biochemical analysis. Results: The data obtained revealed that hyperlipidemic rats had a drastic increase in serum total cholesterol (TC), triacylglycerol (TAG), very low density lipoprotein (vLDL-c), low density lipoprotein (LDL-c) and total lipid levels while, they had marked decrease in serum high density lipoprotein (HDL-c) level suggesting increased atherogenic indices. Also, hyperlipidemia caused significant increase in serum testosterone, progesterone, estradiol, thyroxine (T4) and triiodothyronine (T3) levels, aminotransferases, alkaline phosphatase (ALP), lactate dehydrogenase (LDH) and creatine kinase (CK-MB) activities and troponin-I level with decrease in serum sodium level. Administration of ginger to hyperlipidemic rats reduced serum TC,TAG, VLDL,LDL-c and total lipid levels whileHDL-c was non-significant differed. Furthermore, ALT, AST, ALP, LDH and CK-MB activities and troponin-I level were significantly decreased while serum male sex hormones and thyroid hormones were increased following treatment of ginger. Conclusions: It was concluded that ginger had a protective effect against hyperlipidemia in rats.
\end{abstract}

C 2014 Publisher All rights reserved

\section{Introduction}

Hyperlipidemia, mainly increase level of total cholesterol (TC), triacylglycerol (TAG) and low-density lipoprotein high-density lipoprotein (HDL) cholesterol, is the predictor of coronary artery disease (CAD). Hyperlipidemia is (LDL) cholesterol along with decrease in an important risk factor in the initiation 
and progression of atherosclerotic impasse ${ }^{(1)}$. Hypercholesterolemia is a lipoprotein metabolic disorder characterized by high serum low density lipoprotein and blood cholesterol. Dietary factors such as continuous ingestion of high amounts of saturated fats and cholesterol are believed to be directly related to hypercholesterolemia ${ }^{(2)}$. It has been reported by Rerkasan et al. (3) as one of the most important risk factors in the development and progression of atherosclerosis that lead to cardiovascular diseases (CVDs). Hypercholesterolemia posses a major problem to many societies as well as health professionals because of the close correlation between cardiovascular diseases and lipid abnormalities ${ }^{(4,5)}$.

Triton WR-1339(Tyloxapol: a nonionic detergent, oxyethylated tertiary octylphenol formaldehyde polymer) is used via intravenous or intraperitoneal routes in rodents to produce hypercholesterolemia by accelerating hepatic cholesterol synthesis ${ }^{(6)}$.The levels of serum cholesterol and triglycerides producedby tyloxapol were very high. Cholesterol and oil supplemented diets have been commonly used to produce hyperlipidemiain rats, but the levels of serum lipids have been much lower than produced with tyloxapol. The data on tyloxapolpresented make it possible to achieve high and sustained levels of lipids in a relatively brief time ${ }^{(7)}$.

Ginger rhizome (Zingiber officinale $R$., family: Zingiberaceae) is used worldwide as a spice. Both antioxidative (8) and androgenic activity (9) of $Z$. officinale were reported in animal models. All major active ingredients of Z. officinale such as zingerone, gingerdiol, zingibrene, gingerol and shogaols have antioxidant activity ${ }^{(10)}$. Besides, other researchers showed that ginger oil has dominative protective effect on DNA damage induced by $\mathrm{H}_{2} \mathrm{O}_{2}$ and might act as a scavenger of oxygen radical and might be used as an antioxidant ${ }^{(8)}$. Akhani et al. ${ }^{(11)}$ reported that ginger treatment significantly decreased both serum cholesterol and triacylglycerol. In addition, Fuhrman et al. (12) reported that ginger decreased LDL-cholesterol, VLDL-cholesterol and triacylglycerol levels in apolipoprotein-E deficient mice.

The aim of this study is to throw the light on the effect of Zingiber officinale extract on hyperlipidemic rats through determination of serum lipid profile(TC,TAG,HDL-c, VLDL-c, LDLc, and total lipid), calculation of atherogenic indices, determination of serum ALT, AST, ALP, LDH activities, steroid hormones (progesterone, testosterone, Estradiol) and thyroid hormones $\left(\mathrm{T}_{3}\right.$ and $\left.\mathrm{T}_{4}\right)$, and cardiac biomarkers (CK-MB activity, Troponin I, $\mathrm{Na}$ and $\mathrm{K}$ levels).

\section{MATERIALS AND METHODS}

\subsection{Chemicals and reagents}

Triton WR-1339, biochemical diagnostic kits for cholesterol, triacylglycerol, high density lipoprotein (HDL), total lipids, ALT, AST, ALP, LDH and CK-MB obtained from vitro Scient Co. ELISA diagnostic kits for testosterone, progesterone, estradiol, triiodothyronine (T3) and thyroxine (T4) obtained from Dima Gesellschaft Fur Diagnostika 
[GmbH], Germany. All the reagents used were of analytical grade.

\subsection{Preparation of aqueous extract of ginger}

Ginger powder was purchased from the market of the herbs in Alexandria. Extraction was prepared by soaking 100 $\mathrm{g}$ of the dry ginger roots in $500 \mathrm{ml}$ hot distilled water at 40-50 ¿ with daily shaking for 5 days and kept in a refrigerator. The infusion was evaporated in hot air oven at $50 \mathrm{C}$. known grams of extracts were suspended in distilled water with few drops of Tween 80 to prepare $20 \%$ suspension.

\subsection{Animals and experimental design}

This study was carried out at the Faculty of Veterinary Medicine, Alexandria University. A total 40 male rats of $200 \pm 10 \mathrm{~g}$ b.wt were used and kept in clean metal cages. They were given basal diet which consisted of (bread and corn) and water. All animals were housed under mentioned environmental condition and the basal diet for two weeks before experiment for acclimatization. Animals were divided into 4 groups; control group kept on basal ration and water ad libitum, hyperlipidemic group was received basal ration and hyperlipidemia was induced via intraperitoneal injection of triton WR-1339 (250 $\mathrm{mg} / \mathrm{kg} \quad$ b.wt $)$ three times/week for three weeks, ginger aqueous extract treated rats received basal ration and aqueous extract of ginger $400 \mathrm{mg} / \mathrm{kg}$ b.wt given daily by stomach tube and aqueous extract of ginger + triton group kept on basal ration, aqueous extract of ginger and triton WR-1339 (at the same previous dose with the same route of administration).

\subsection{Collection of blood samples}

Blood samples were drawn from the retro-orbital plexus of rats under diethyl ether anesthesia before sacrificing by decapitation. The blood samples were collected without anticoagulant for obtaining serum for biochemical analysis. Blood samples were collected in clean dry tubes and left in slope position to clot at room temperature. The tubes were centrifuged at $3000 \mathrm{rpm}$ for 5 minutes and clear serum sample was carefully separated then transferred into clean dry eppindorf and kept frozen at $20{ }^{\circ} \mathrm{C}$ until analysis.

\subsection{Biochemical analysis}

Lipid profile were determined spectrophotometry using commercial diagnostic kits; TC was determined according to ${ }^{(13)}$, TAG according to ${ }^{(14)}$,HDL-c according to ${ }^{(15)}$, LDL-c according to ${ }^{(16)}$,total lipid according to (17), Atherogenic indices were calculated according to ${ }^{(18)}$, serum ALT and AST activities were determined according to (19), serum ALP activity according to ${ }^{(20)}$, LDH activity according to ${ }^{(21)}$, CK-MB activity according to ${ }^{(19)}$, serum $\mathrm{Na}$ level was determined according to (22) and serum $\mathrm{K}$ level according to ${ }^{(23)}$. Serum Troponin I level was determined using ELISA kits according to ${ }^{(24)}$, testosterone, estradiol were determined according to (25), progesterone was determined according to ${ }^{(26)}, \mathrm{T}_{3}$ was determined according to ${ }^{(27)}$ and $\mathrm{T}_{4}$ was determined according to ${ }^{(28)}$.

\subsection{Statistical analysis}

Statistical analysis was performed by using computer of statistical package for 
social science (SPSS version 11.0). The results are presented as means \pm SE. One way analysis of variance (ANOVA) was used to test the differences between groups ${ }^{(29)}$.

\section{RESULTS AND DISCUSSION}

The main causative factor for atherothrombotic diseases is the disturbances occurring in lipid metabolism. Hypercholesterolemia is an important risk factor for cardiovascular disease ${ }^{(30)}$. Hypercholesterolemia itself is asymptomatic, longstanding elevation of serum cholesterol can lead to atherosclerosis ${ }^{(31)}$. Though there is a large class of hypolipidemic drugs used in the treatment, none of the existing ones available worldwide is fully effective, absolutely safe and free from side effects ${ }^{(32)}$. Hence efforts are being made to find out safe and effective agents that may be beneficial in correcting the lipid metabolism and preventing cardiac diseases.

Ginger

(ZingiberofficinaleRosc.), belonging to a tropical and sub-tropical family Zingiberaceae, introduced to many parts of the globe, has been cultivated for thousands of years as a spice and for medicinal purposes ${ }^{(33)}$.

Our results represented in table (1) showed that injection of rats with Triton WR-1339 induced drastic increase in serum total cholesterol, triacylglycerol, LDL-c, VLDL-c levels and decreased serum HDL-c level which may be attributed to elevated hepatic cholesterol synthesis particularly by the increase in HMG Co-A activity and by the inhibition of lipoprotein lipase responsible for hydrolysis of plasma lipids ${ }^{(34)}$. These results were in agreement with
Sivaelango et al. (35) who found that hyperlipidemia was induced in Wistar rats by intraperitoneal (i.p) injections of Triton WR-1339 at a dose of $400 \mathrm{mg} / \mathrm{kg}$ body weight. Also, Bertges et al. (36) reported that intraperitoneal injection of TritonWR-1339 at a dose of $200 \mathrm{mg} / \mathrm{kg}$ b.wt induced hyperlipidemia in rats. Administration of ginger extract significantly reduced serum cholesterol, TAG, LDL-c, VLDL-c levels with increase in serum HDL-c level (table 1). This result agree with Ajayi ${ }^{(37)}$ who found that treatment with $5 \%$ and $10 \%$ ginger powder for 6 weeks a significant reduction was observed in the total cholesterol concentrations compared to the hypercholesterolemic fed rats. Also, El-Bushuty and Shanshan ${ }^{(38)}$ found that rats treated with ginger showed a significant decrease in the values of serum cholesterol, triacylglycerol, LDL-c and VLDL-c. Furthermore, Soni et al. ${ }^{(39)}$ reported that consumption of $500 \mathrm{mg}$ of curcumin (a constituent of ginger) by volunteers for 10 days induced an increase in HDL-c by $29 \%$. However, treatment of ginger juice for 10 days at a dose of $4 \mathrm{ml} / \mathrm{Kg}$ b.wt orally to normal non-diabetic rats did not produce significant lipid lowering effects ${ }^{(40)}$. It had been reported that ginger stimulated the conversion of cholesterol to bile acids, the activity of hepatic cholesterol7 alpha-hydroxylase, the rate-limiting enzyme of bile acid biosynthesis from cholesterol, was significantly elevated in ginger-treated animals ${ }^{(41)}$, and increasing fecal cholesterol excretion ${ }^{(42)}$.

In our study, the serum HDL-c showed non-significant change in hypercholesterolemic pretreated with 
ginger extract compared with Triton WR1339 treated rats. This result agreed with (41) who reported non-significant change in serum HDL-c level in high fat diet rats, treated with ginger extract ta dose 200 and $400 \mathrm{mg} / \mathrm{Kg}$ b.wt compared to control group. On the other hand, the plasma HDL-c significantly increased in hypercholesterolemic rattreated with ginger powder $5 \%$ and $10 \%$ for 6 weeks (37). These discrepancies in results may be due to different constituents between ginger powder and extract.

The data observed in table (2) showed that hypercholesterolemic rats had high atherogenic indices and treatment with ginger showed antiatherogenic activity. These results were confirmed by these obtained by Deviand Rajkumar ${ }^{(43)}$ who found that atherogenic index was increased in HFD fed rats as compared to control. Also, Raj et al. ${ }^{(44)}$ reported that atherogenic Index (AI) and Coronary Risk Index (CRI) were increased in Triton WR-1339 induced hyperlipidemic rats. El-yamani (45) reported that administration of ginger powder $7 \%$ in experimental diet significantly reduced the atherogenic index in alloxan induced diabetic rats as compared to control. Tijjaniand Luka ${ }^{(46)}$ demonstrated that administration of aqueous extract of ginger at dose of $400 \mathrm{mg} / \mathrm{kg}$ b.wt significantly reduce atherogenic index (AI) of treated rats when compared to HLD rats.

Our results in table (3) revealed thathypercholesterolemic rats had significant elevated liver function enzymes as compared to control group. These results were confirmed by those obtained by Deviand Rajkumar ${ }^{(43)}$ who found that rats fed high fat diet had elevated serum ALT, AST, LDH and ALP activities.Also, Taha et al. ${ }^{(47)}$ found thatintraperitoneal injection of Triton WR-1339 at dose of $(250 \mathrm{mg} / \mathrm{kg} / 3$ times/week) showed a significant increase in serum activities of AST, ALT and GGT enzymes as compared to control group. While, Umar et al. ${ }^{(48)}$ found that feeding rats high fat diet did not significantly increase activities of AST and ALT enzymes. Also, our results revealed that administration of ginger extract significantly reduced serum ALT, AST, ALP and LDH activities (table 3).

This may be attributed to their antioxidant activity and high level of its flavonoids that have the ability to scavenge free radicals. These came coincide with those obtained by Motawi et al. ${ }^{(49)}$ who found that rats treated with Ginger (ethanol, chloroform and petroleum ether) extracts orally at a dose $200 \mathrm{mg} / \mathrm{kg}$ significantly decreased AST, ALT ALP, GGT enzymatic activities and total bilirubin level. Also, Lebda et al. ${ }^{(50)}$ reported that serum ALT, AST, ALP and GGT enzymatic activities were significantly decreased in rabbits fed basal diet for 30 days supplemented with $2 \%$ ginger powder and hot and cold aqueous ginger extracts. On other hands, these disagreed with Alnaqeeb et al. ${ }^{(51)}$ who mentioned that administration of aqueous extract of ginger at dose 500 $\mathrm{mg} / \mathrm{kg}$ in rats by i.p route significantly increased liver LDH with non-significant changes in AST and ALT activities.

The data in table (4) revealed that administration of Triton WR-1339 significantly increased serum testosterone, estradiol, progesterone, $\mathrm{T}_{3}$ 
and $\mathrm{T}_{4}$ levels as compared to control group. Also, our results revealed that administration of ginger extract significantly increased progesterone, estradiol, testosterone, while $\mathrm{T}_{3}$ and $\mathrm{T}_{4}$ were non-significant changed while, and administration of ginger extract to hyperlipidemic rats significantly increased serum $\mathrm{T}_{3}, \mathrm{~T}_{4}$ and testosterone levels. These results were in accordance with Azhar and Menon ${ }^{(52)}$ who found that injection of rats with Triton-WR$1339(1 \mathrm{~g} / \mathrm{kg}$ b.wt) every $12 \mathrm{~h}$ for 1,2 or 3 days slightly increased plasma testosterone level on day 2 and day3. Also, Sulcova et al. ${ }^{(53)}$ reported that hyperlipidemic patient significantly had high levels of estradiol and there was a higher index of free testosterone due to the significantly lower SHBG level. Furthermore, Attyha et al. ${ }^{(54)}$ found a significant elevation of estradiol level in atherosclerotic hyperlipidemic patient when compared with those of control group. Moreover, Leahy and Mcnickle ${ }^{(55)}$ reported that Triton treatment resulted in a significantly decreased uptake of triiodothyronine in the erythrocytic system and, conversely, a significantly increased binding of triiodothyronine by plasma. While, Leahy et al. (56) demonstrated that unchanged levels of plasma thyroid hormone suggest that Triton WR-1339 does not stimulate the thyroid gland directly. The increased rate of thyroxin disappearance could be explained by an indirect stimulation of the gland resulting from increased activity of a hormone-degrading enzyme system at the tissue level.

Ginger also hasanti-oxidative, antiinflammatory and androgenic activities,
Khaki et al. (8) revealed that administration of $100 \mathrm{mg} / \mathrm{kg} /$ day of ginger significantly increased sperm percentage, viability, and motility and serum total testosterones. On the other hands, Lebda et al. ${ }^{(50)}$ reported that testosterone hormone concentration in rabbits fed basal diet supplemented with $2 \%$ ginger powder and ginger hot and cold extracts for 30 days was significantly decreased in all gingertreated groups as compared to control. Studies have shown effects of ginger on metabolism. Thyroid hormones have a regulatory role on metabolism which may be influenced by ginger. The ginger has antioxidative, antidiabetic effects and presser activity in rats Islam and Choi (57). It is a safe herb and up to now, significant side effects such as thyroiditis have not been reported. Despite its experimental antioxidative and inhibitory effects on metabolic rate, which theoretically may lead to decreased thyroid hormone synthesis, ginger is presumed to play a role in subacute thyroiditis induction. Riewe et al. (58) reported that inhibitory effect of ginger on metabolic rate and adenylate energy status may damage the integrity of membranes surrounding the thyroid hormones in follicles and eventually release hormones into circulation. Also, subacute thyroiditis may be induced due to an autoimmune process by ginger as an antigen, which changes antigenic properties of thyroid follicular cells. Although, allergic reactions to ginger are generally reported as skin rash, it may promote wider inflammatory responses. It would be interesting to investigate whether this alleged adverse effect has 
any genetic predisposition. Further research is needed to understand the possible effects of ginger on thyroid gland. Ginger contains magnesium, which has been shown to be a critical in controlling thyroid disease ${ }^{(59)}$ but only a little research study ginger's effect on thyroid function.

Regarding cardiac biomarkers, our results showed that serum levels of Troponin-I and CK-MB enzymatic activity were significantly increased in hyperlipidemic rats. However, serum sodium level significantly decreased and serum potassium level not significantly changed in hyperlipidemic rats. Also, treatment with ginger extract significantly decreased serum CK-MB activity, troponin-I and $\mathrm{K}$ levels and $\mathrm{Na}$ not significantly changed (table 5).These were in coincide with Suanarunsawatet al. (60) who reported thatCK-MB enzymatic activity was significantly increased in rats fed with highcholesterol (HC) diet for seven weeks.Also, Kumar andSathian (61)found that elevated levels of TC, LDL-c, and TAG with significantly reduced HDL-c had positive troponin test but there are lack of previously published research papers on the relationship between lipid profiles and troponin test. Treatment with ginger extract significantly decreased serum levels of Troponin-I and CK-MB. These results confirmed by Rohini et al. ${ }^{(62)}$ who found that administration of ethanolic extract of ginger at dose $(200$ and $400 \mathrm{mg} / \mathrm{kg}$ per day orally) attenuated PAAC induced increase in CK-MB and LDH levels. Furthermore, Medi ${ }^{(63)}$ demonstrated that oral pretreatment with ginger at dose of
(200 and $400 \mathrm{mg} / \mathrm{kg}$ b.wt) significantly restored the activity of CK-MB enzyme, and Troponin-I level near normal level in both heart and serum in doxorubicin induced cardiotoxicity in rats.

Prasad ${ }^{(64)}$ found that feeding rabbits on high cholesterol diet did not affect potassium. Also, Kim ${ }^{(65)}$ reported that patients with hyponatremia, pseudohyponatremia suffer from high concentrations of intravascular protein (as in multiple myeloma) or lipid dilute the plasma sodium concentration, but do not alter the solute concentrations of the intracellular or interstitial fluid compartments, thus hyponatremia associated with hyperlipidemia or hyperproteinemia can be considered art factual, and is called pseudohyponatremia. On the other hand, hypercholesterolemia did not affect serum sodium level in rabbits ${ }^{(64)}$. Ginger was proved more potent renoprotective agent in both acute and chronic renal failure (CRF) and the mechanisms underlying the effects of renal failure by ischemia-reperfusion ${ }^{(66)}$. Also, Maralla ${ }^{(67)}$ reported that administration of ginger extract for 6 weeks on kidney functions in withdrawal rats to evaluate the ameliorating effects in alcohol inducedwithdrawal rats is capable of improving hyperlipidemia and the impaired kidney functions in ethanol induced-withdrawal rats maintaining proper kidney functioning as well as maintaining electrolyte balance preventing retention of solutes. Furthermore, Kazeemet al. ${ }^{(68)}$ found that consumption of ginger at different concentration in basic diet of rats significantly reduced potassium ion and levels of sodium ion was not 
significantly affected by the presence of ginger in the experimental diets.

\section{Conclusion}

It was concluded that hyperlipidemia induced by administration of Triton WR1339 in rats had adverse effect on serum lipid profile, increasing atherogenic indices, increasing hepatic and cardiac enzymes indicating their damage. Also, hyperlipidemia disturbs male sex hormone and thyroid hormones. Administration of ginger attenuated these adverse effects of hyperlipidemia suggesting a protective effect of ginger.

\section{References}

(1) Sikarwar, M.S. and M.B. Patil., 2012.Antihyperlipidemic activity of Salacia chinensis root extracts in triton-induced and atherogenic diet induced hyperlipidemic rats. Indian J Pharmacol; 44: 88-92.

(2) Asashina, M., M, Sato and K,Imaizumi., 2005.Genetic analysis of diet induced hypercholesterolemia in exogenously hypercholesterolemic (ExHC) rats. J Lipid Res, 46: 2289-2294.

(3) Rerkasen, K., P.J. Gallagher., R.F. Grimble., P.C. Calder, and C.P. Shearman., 2008. Managing hypercholesterolemia and its correlation with carotid plaque morphology in patients undergoing carotid endoterectomy. Vascular Health Risk Manage, 4 (6):12591264.

(4) Ramachandran, H.D., K, Narasimhamurthy, and P.L. Raina., 2003. Modulation of cholesterol induced hypercholesterolemia through dietary factors in Indian desert gerbils (Merioneshurricinae). Nutr Res, 23: 245-256.

(5) Matos, S. L., H, Paula., M.L. Pedrosa., R.C. Santos., E.L. Oliveira., D.A. ChiancaJr, and M.E.
Silva., 2005. Dietary models for inducing hypercholesterolemia in rats. Brazilian Archives Biol Technol, 48(2): 203- 209.

(6) Majithiya, J.B., A.N. Parmar and R, Balaraman., 2004. Effect of curcumin on triton WR 1339 induced hypercholesterolemia in mice. Indian J Pharmacol, 36 (6): 381-384.

(7) Levine, S. and A, Saltzman., 2007. A procedure for inducing sustained hyperlipidemia in rats by administration of a surfactant.J. Pharmacol and Toxicol Methods, 55: 224-226.

(8) Khaki, A., F, Fathiazad., M, Nouri., A. A. Khaki., C.C. Ozanci., M, Ghafari-Novin and M, Hamadeh., 2009. The Effects of Ginger on Spermatogenesis and Sperm parameters of Rat. Iranian J Reprod Med, 7: 7-12.

(9) Kirtikar, K.R. and B.D. Basu., 1991. "Indian Medicinal Plants", 2nd ed., Periodical Export, New Delhi

(10) Nassiri, M., A, Khaki., S.H. Gharachurlu., A, Ashteani., H, Rastegar, and S.H. Rezazadeh., 2009. Effects of Ginger on spermatogenesis in Streptozotocininduced Diabetic Rat. Iran J Med Plants, 8 (31):118-124.

(11) Akhani, S., S, Vishwakarma and R.K. Goyal., 2004. Anti-diabetic activity of Zingiber officinale in Streptozotocin-induced type I diabetic rats. $\mathbf{J}$ of Pharmacy and Pharmacal, 56: 101-105.

(12) Fuhrman, B., M, Roseblate., T, Hayek., R, Coleman and M, Aviram., 2000. Ginger Extract Consumption Reduces Plasma Cholesterol, Inhibits LDL Oxidation and Attenuates Development of Atherosclerosis in Atherosclerotic, Apolipoprotein E-Deficient Mice. J Nutr, 130: 1124-1131. 
(13) Searcy, R.L. 1969. Diagnostic Biochem.McGraw-Hill, New York, NY.

(14) Stein, E.A. 1987. Lipids, lipoproteins. Tietz NW. Fundementals of clinic chem. $3^{\text {rd }} \mathrm{ED}$ : 448-4481. Philadelphia: WB Saunders

(15) Friedewald, W.T, R.I. Levy and D.S. Fredrickson, 1972.Estimation of the concentration of low-denisty lipoprotein cholesterol in plasma, without use of the preparative ultracentrifuge. Clin Chem, 18: 499502.

(16) Bauer, J.D. 1982.Clinical laboratory methods. $9^{\text {th }}$ ED: 555, The C.V. company, Westline Industrial Missouri.

(17) Zöllner, N. and K.Z. Kirsch., 1962. Cited in Biosystem kits for determination of total lipids concentration.GesExp Med, 135: 545-561.

(18) Brehm, A., G, Pfeiler., G, Pacini., H, Vierhapper and M, Roden., 2004.Relationship between serum lipoprotein ratios and insulin resistance in obesity. Clin Chem, 50: 2316-2322.

(19) Young, D.S. 1990. Effect of drugs on clinical laboratory tests. $3{ }^{\text {rd }} \mathrm{ED}: 6$ 12.

(20) Tietz, N.W., A.D. Rinker, and L.M. Shaw., 1993. IFCC methods for the measurement of catalytic concentration of enzymes.Part 5.IFCC method for alkaline phosphatase. J Clin Chem Clin Biochem, 21: 731-748.

(21) Tietz, N.W. 1995.Clinical guide to laboratory tests. 3rd Ed., (W.B.saunders.eds. Philadelphia USA), 384.

(22) Trinder, P. 1951. Cited in biosystem kits for determination of sodium concentration. Analyst, 76: 596.
(23) Eden, A and H.H. Green., 1940.Cited in biosystem kits for determination of potassium concentration. Biochem J 34:1202.

(24) Mair, J., C, Larue., P, Mair., D, Balogh., C, Calzolari and F.B. Puschendor., 1994. Use of cardiac troponin- I to diagnosis perioprative myocardial infarction in coronary artery by passgraftin.Clinchem, 40: 2066-2070.

(25) Tietz, N.W. 1986. Textbook of Clinical Chemistry. Saunders.

(26) Katt, J.A., J.A. Duncan., L, Herbon., A, Barkan and J. C. Marshall., 1985. The frequency of gonadotropin releasing hormone stimulation determines thenumber of pituitary gonadotropin releasing hormone receptors. Endocrinology; 116:21132118

(27) Tietz, N.W. 1987. Fundamentals of Clinical Chemistry, p. 588. Saunders Press, Philadelphia

(28) Stein, R.B. and L, Price., 1972. Evaluation of adjusted total thyroxine (free thyroxine index) as a measure of thyroid function. J Clin Endocrinol Metab, 34 (1): 225-228

(29) SPSS 1999. SPSS-PC for the IBM PC/XT computer.version 11.0 SPSS Inc., U.S.A.

(30) Van der Wulp, M.Y.M., J, Henkjan., A, Verkade, and A.K. Groen., 2013. Regulation of cholesterol homeostasis; Molecular and Cellular Endocrinology, 368: 1-16.

(31) Bhatnagar, D., H, Soran and P.N. Durrington., 2008.Hypercholesterolemia and its management". BMJ 337: 993-997.

(32) Kothiyal, P. and A.K. Gupta., 2011. Antihyperlipidemic activity of aqueous and ethanolic extracts of fruits of Kigeliaafricana(Lam.) Benth. In Triton X-100 induced hyperlipidemic rats. Pharmacology online,3: 386-395. 
(33) Park, E.J. and J.M. Pizzuto., 2002. Botanicals in cancer chemoprevention Cancer. Metastasis Review, 21: 231-255.

(34) Ngondi, J.L., C.F.B. Nyangono., R.M.C. Naganoum., D, Kuate, and J.E. Oben., 2012. Effect of Guibourtiatessmannii extracts on blood lipids and oxidative stress markers in triton WR 1339 and high fat diet induced hyperlipidemic rats. Biol and Med Res, 4 (1): 01-09.

(35) Sivaelango, G., P, SenthilKumaran., P, Kumaravel., P, Revathi, and A, Jaswant., 2012. Antihyperlipidaemic Activity of

SpermacoceHispidaEthanolic Extract in Triton WR-1339 Induced Hyperlipidaemic Rats. J of Applied Pharmaceutical Science, 02 (02): 9598.

(36) Bertges, L.C., C.A, MourãoJr., J.B. Souza and V.A. Coelho Cardoso., 2011. Hyperlipidemia induced by Triton WR1339 (Tyloxapol) in Wistar rats. Rev Bras Cien Med Saúde, 1 (1): 32-4.

(37) Ajayi, O., 2011.Effect of Ginger Powder (Zingiber Officinale) on Plasma Lipid Profile and Liver Enzyme Activities of Hypercholesterolemic Rats. J of Life Sciences, 5: 712-716

(38) EL Bushuty, D.H and N.M. Shanshan., 2012.Effect of natural herbs of marjoram and Ginger on hypercholesterolemic rats.Faculty of Specific Education - Mansoura University. Egypt, 1754-1767

(39) Soni, K.B., A, Rajan, and R, Kuttan., 1992. Reversal of aflatoxin induced liver damage by turmeric and curcumin. Cancer Lett, 66: 115121.

(40) Sultana, S., S, Akter, and I.M.D.khan.,2012. antihyperlipidemic action of zingiberofficinale (ginger) juice in alloxan induced diabetic rats. Med Coll J, 6(2): 55-58.

(41) Srinivasan, K. and K, Sambaiah., 1991. The effect of spices on cholesterol 7-alpha hydroxylase activity and on serum and hepatic cholesterol levels in the rat. International Journal of Vitamins and Nutrition Research, 61 (4): 364 369.

(42) Sharma, I., D,Gusain, and V.P. Dixit., 1996. Hypolipidemic and antiatherosclerotic effects of Zingiberofficinale in cholesterol-fed rabbits.PhytoRes, 10:517- 518.

(43) Devi, J and J, Rajkumar., 2013.Antihyperlipidemic effect of ambrex, a polyherbal formulation against experimentally induced hypercholesterolemia in rats. Afr $\mathbf{J}$ PharmPharmacol, 7 (25): 1737-1743.

(44) Raj, D.A., T, Malarvili, and S, Velavan., 2014. Evaluation of hypolipidemic activity of betulaalnoides bark on triton wr1339 induced hyperlipidemia in albino rats. American Journal of Pharmaceutical Sciences, 1(1): 1-5.

(45) El-yamani, M. A. S. 2011. Cinnamon, cardamom and ginger Impacts as evaluated on Hyperglycemic rats. Research Journal Specific Education 20: 664679

(46) Tijjani, H. and C.D. Luka., 2013. Effects of Afromomummelegueta, Zingiberofficinale and Piper nigrum on Some Biochemical and Haematological Parameters in Rats Fed with High Lipid Diet. Int J Pure App Biosci, 1(3): 61-67.

(47) Taha, N., M, Korshom., A, Mandour., M, Lebda., A, ELMorshedy, and O, Walaa., 2013. Biochemical Evaluation of Hypolipidemic Effect of Rice Bran Oil in Induced Hyperlipidemic Rats. 
Tanta Medical Sciences J, 8 (1): 25 39

(48) Umar, I.A., A, Mohammed., F.A. Dawud., A.M. Kabir., J.V. Sai., F.S. Muhammad, and M.E. Okalor., 2012. The hypolipidemic and antioxidant actions of aqueous extracts of Ocimumbasilicum and Ocimum suave in high fat fed rats. $\mathbf{J}$ Med plants Res, 6 (18): 3501-3505.

(49)Motawi, T.K., M.A. Hamed., M.H. Shabana., R.M.Hashem, and A.F. AboulNaser., 2011. Zingiber officinale acts as a nutraceutical agent against liver fibrosis. journal ListNutrMetab (Lond), 8( 40): 1-11.

(50) Lebda, M.A., N.M. Taha., M.A. Korshom., A.A. Mandour and A.M. EL-Morshedy., 2012. Biochemical effect of ginger on some blood and liver parameters in male newzeland rabbits. Online J Anim Feed Res, 2(2): 197-202.

(51) Alnaqeeb, M. A., M,Thomson.,K, Al-Qattan., F, Kamel., T, Mustafa and M, Ali., 2003.Biochemical and histopathological toxicity of an aqueous extract of ginger in female rats.Kuwait J Sci Eng, 30 (2): 3548.

(52) Azhar, S.K. and M.J. Menon., 1982. Receptor mediated gonadotropin action in Gonadal tissues: relationship between blood Cholesterol levels and gonadotropin Stimulated steroidogenesis in isolated Rat leydig and luteal cells. J of steroid biochemistry, 16: 175-184.

(53) Šulcova, J., T, Štulc., M, Hill., R, Hampl., Z, Mašek., K, Vondra, and R, Češka., 2005. Decrease in Serum Dehydroepiandrosterone Level after Fenofibrate Treatment in Males with Hyperlipidemia. Physiol Res, 54: 151-157.

(54) Attyha, I. N., E.M. Turki and J.M. Husan., 2013.Effect of hyperlipidemia in the atherosclerotic patients on sex hormones.Magazin of Al-Kufa University for Biology, 5 (2):321-326.

(55) Leahy, W.V.C. and T.F. McNickle., 1963. The binding of thyroidal hormones by triton wr-1339. Canadian Journal of Biochemistry and Physiology, 41(8):1803-1809.

(56) Leahy, W.V.C., B.W. Janicki and T.F. McNickle., 1961. Effect of Triton WR-1339 on thyroid activity of normal guinea pigs. American Journal of Physiology, 201: 827-829

(57) Islam, M.S. and H, Choi., 2008. Comparative effects of dietary ginger (zingberofficinale) and garlic (allium sativum) investigated in a type 2 diabetes model of rats. $\mathrm{J}$ Med Food 11: 152-159.

(58) Riewe, D., L, Grosman., H, Zauber., C, Wucke., A.R. Fernie, and P, Geigenberger., 2008. Metabolic and developmental adaptations of growing potato tubers in response to specific manipulations of the adenylate energy status. Plant Physiol, 146: 1579-1598.

(59) Alizadeh-Navaei, R., F,Roozbeh.,M,Saravi., M,Pouramir., F, Jalali and A.A. Moghadamnia., 2008.Investigation of the effect of ginger on the lipid levels. A double blind controlled clinical trial. Saudi Med J, 29: 1280-1284.

(60) Suanarunsawat, T., N.A, Devakul., W, Ayutthaya., T, Songsak., S, Thirawarapan, and $\mathrm{S}$, Poungshompoo., 2011.LipidLowering and Antioxidative Activities of Aqueous Extracts of Ocimum sanctum L. Leaves in Rats Fed with a High-Cholesterol Diet. Oxidative Medicine and Cellular Longevity, 2011: 1-9.

(61) Kumar, A. and B, Sathian., 2013. Correlation between lipid profile and troponin I test results in patients with 
chest pain in Nepal.. Asian Pac J Trop Biomed, 3(6): 487-491.

(62) Rohini, A., N, Agrawal., M.J.N. Chandrasekar, and U.V.S. Sara., 2013. Evaluation of Cardioprotective Effect of Zingiber Officinale in Experimental Animals. International Journal of Current Pharmaceutical Review and Research, 4(1): 1-9.

(63) Medi, S. 2011. Pharmacodynamics interaction of ethanolic extract of ginger with simvastatinin doxorubicin induced oxidative myocardial damage in wistarrats. A thesis of master in pharmacology, KLE university, Belgaum, Karnataka, 106.

(64) Prasad, K. 2010. Effects of vitamin $\mathrm{E}$ on serum enzymes and electrolytes

inhypercholesterolemia. Mol Cell Biochem 335: 67-74.

(65)

Kim,

G.H.

2006.Pseudohyponatremia: Does It
Matter in Current Clinical Practice? Electrolyte \& Blood Pressure, 4: 7782.

(66) Mahmoud, M.F., A.A. Diaai and F, Ahmed., 2012. Evaluation of the Efficacy of Ginger, Arabic Gum, and Boswellia in Acute and Chronic Renal Failure. Renal Failure, 34 (1): 73-82.

(67) Maralla, S. 2013. Effect of Ginger Extract Consumption on Renal Function during Ethanol Withdrawal Induced-Stress. International Journal of Innovative Research in Science, Engineering and Technology (IJIRSET), 2 (11): 6412-6418.

(68) Kazeem, M.I., H.A. Bankole and A.A. Fatai., 2011.Protective effect of ginger in normal and carbontetrachloride induced hepatotoxic rats. Annals of Biological Research, 2 (1): $1-8$ 
Table (1): Effect of ginger aqueous extract on serum lipid profile in hyperlipidemic rats

\begin{tabular}{|c|c|c|c|c|c|c|}
\hline Groups & TC $(\mathrm{mg} / \mathrm{dl})$ & TG (mg/dl) & $\begin{array}{c}\text { HDL-c } \\
(\mathrm{mg} / \mathrm{dl})\end{array}$ & $\begin{array}{c}\text { vLDL-c } \\
(\mathrm{mg} / \mathrm{dl})\end{array}$ & $\begin{array}{c}\text { LDL-c } \\
(\mathrm{mg} / \mathrm{dl})\end{array}$ & $\begin{array}{c}\text { T. Lipid } \\
(\mathrm{mg} / \mathrm{dl})\end{array}$ \\
\hline \multirow{2}{*}{ I } & $95.66 \pm$ & $63.62 \pm$ & $30.14 \pm$ & $18.21 \pm$ & $39.47 \pm$ & $251.95 \pm$ \\
& $4.40^{\mathbf{c}}$ & $3.76^{\mathbf{c}}$ & $2.50^{\mathbf{b}}$ & $1.08^{\mathbf{b}}$ & $3.63^{\mathbf{c}}$ & $12.92^{\mathbf{c}}$ \\
\hline \multirow{2}{*}{ II } & $77.28 \pm$ & $51.22 \pm$ & $36.98 \pm$ & $15.66 \pm$ & $29.26 \pm$ & $225.47 \pm$ \\
& $3.33 \mathrm{c}^{\mathbf{d}}$ & $2.81^{\mathbf{c}}$ & $2.65^{\mathbf{a}}$ & $0.34^{\mathbf{b}}$ & $0.59^{\mathbf{c}}$ & $20.17^{\mathbf{c}}$ \\
\hline \multirow{2}{*}{ III } & $311.5 \pm$ & $582.61 \pm$ & $1.60 \pm$ & $128.39 \pm$ & $174.65 \pm$ & $1234.50 \pm$ \\
& $9.47^{\mathbf{a}}$ & $23.38^{\mathbf{a}}$ & $0.15^{\mathbf{c}}$ & $18.16^{\mathbf{a}}$ & $16.94^{\mathbf{a}}$ & $150.94^{\mathbf{a}}$ \\
\hline \multirow{2}{*}{ IV } & $246.24 \pm$ & $483.91 \pm$ & $1.61 \pm$ & $120.55 \pm$ & $125.85 \pm$ & $1086.56 \pm$ \\
& $8.81^{\mathbf{b}}$ & $11.48^{\mathbf{b}}$ & $0.16^{\mathbf{c}}$ & $10.31^{\mathbf{a}}$ & $10.65^{\mathbf{b}}$ & $54.55^{\mathbf{a}}$ \\
\hline
\end{tabular}

The values are mean \pm S.E. Means with different superscript letter in the same column are significantly differ at $\mathrm{P}<0.05$. I; control group, II; aqueous ginger extract group, III; hyperlipidemic group, IV; hyperlipidemic pretreated group.

Table (2): Effect of aqueous extract of ginger on atherogenic indices in hyperlipidemic rats

\begin{tabular}{|c|c|c|c|}
\hline Groups & CRR & AC & AI \\
\hline I & $3.30 \pm 0.41^{\mathbf{c}}$ & $2.30 \pm 0.41^{\mathbf{c}}$ & $0.33 \pm 0.04^{\mathbf{b}}$ \\
\hline II & $2.14 \pm 0.13^{\mathbf{c}}$ & $1.14 \pm 0.13^{\mathbf{c}}$ & $0.15 \pm 0.03^{\mathbf{c}}$ \\
\hline III & $209.35 \pm 20.48^{\mathbf{a}}$ & $208.35 \pm 20.48^{\mathbf{a}}$ & $2.50 \pm 0.05^{\mathbf{a}}$ \\
\hline IV & $164.02 \pm 15.55^{\mathbf{b}}$ & $163.05 \pm 15.57^{\mathbf{b}}$ & $2.48 \pm 0.05^{\mathbf{a}}$ \\
\hline
\end{tabular}

The values are mean \pm S.E. Means with different superscript letter in the same column are significantly differ at $\mathrm{P}<0.05$. I; control group, II; aqueous ginger extract group, III; hyperlipidemic group, IV; hyperlipidemic pretreated group.

Table (3): Effect of aqueous extract of ginger on serum liver function tests in hyperlipidemic rats

\begin{tabular}{|c|c|c|c|c|}
\hline Groups & $\begin{array}{c}\text { ALT } \\
(\mathrm{U} / \mathrm{L})\end{array}$ & $\begin{array}{c}\text { AST } \\
(\mathrm{U} / \mathrm{L})\end{array}$ & $\begin{array}{c}\text { ALP } \\
(\mathrm{U} / \mathrm{L})\end{array}$ & $\begin{array}{c}\text { LDH } \\
(\mathrm{U} / \mathrm{L})\end{array}$ \\
\hline I & $40.12 \pm 1.63^{\mathbf{c}}$ & $98.81 \pm 3.17^{\mathbf{c}}$ & $704.62 \pm 24.90^{\mathbf{b}}$ & $889.20 \pm 34.89^{\mathbf{b}}$ \\
\hline II & $19.83 \pm 0.67^{\mathbf{d}}$ & $89.11 \pm 1.58^{\mathbf{c}}$ & $408.44 \pm 30.97^{\mathbf{c}}$ & $609.10 \pm 49.63^{\mathbf{b}}$ \\
\hline III & $108.94 \pm 4.74^{\mathbf{a}}$ & $262.89 \pm 23.32^{\mathbf{a}}$ & $878.08 \pm 43.60^{\mathbf{a}}$ & $1707.22 \pm 158.48^{\mathbf{a}}$ \\
\hline IV & $91.34 \pm 5.33^{\mathbf{b}}$ & $180.42 \pm 14.08^{\mathbf{b}}$ & $732.08 \pm 33.39^{\mathbf{b}}$ & $1485.34 \pm 83.50^{\mathbf{a}}$ \\
\hline
\end{tabular}

The values are mean \pm S.E. Means with different superscript letter in the same column are significantly differ at $\mathrm{P}<0.05$. I; control group, II; aqueous ginger extract group, III; hyperlipidemic group, IV; hyperlipidemic pretreated group. 
Table (4): Effect of aqueous extract of ginger on serum testosterone, estradiol, progesterone, triiodothyronine and thyroxine hormonal levels in hyperlipidemic rats

\begin{tabular}{|c|c|c|c|c|c|}
\hline Group & $\begin{array}{c}\text { Progesterone } \\
(\mathrm{ng} / \mathrm{ml})\end{array}$ & $\begin{array}{c}\text { Estradiol } \\
(\mathrm{Pg} / \mathrm{ml})\end{array}$ & $\begin{array}{c}\text { Testosterone } \\
(\mathrm{ng} / \mathrm{ml})\end{array}$ & $\begin{array}{c}\text { T3 } \\
(\mathrm{ng} / \mathrm{ml})\end{array}$ & $\begin{array}{c}\text { T4 } \\
(\mu \mathrm{g} / \mathrm{dl})\end{array}$ \\
\hline I & $0.04 \pm 0.00^{\mathbf{b}}$ & $7.17 \pm 1.16^{\mathbf{b}}$ & $0.25 \pm 0.05^{\mathbf{c}}$ & $1.01 \pm 0.06^{\mathbf{d}}$ & $2.90 \pm 0.29^{\mathbf{c}}$ \\
\hline II & $0.34 \pm 0.01^{\mathbf{a}}$ & $9.29 \pm 0.27^{\mathbf{b}}$ & $1.71 \pm 0.05^{\mathbf{b}}$ & $0.76 \pm 0.02^{\mathbf{d}}$ & $2.17 \pm 0.15^{\mathbf{c}}$ \\
\hline III & $0.36 \pm 0.01^{\mathbf{a}}$ & $52.15 \pm 0.17^{\mathbf{a}}$ & $3.06 \pm 0.03 \mathrm{~b}^{\mathbf{a}}$ & $6.71 \pm 0.04^{\mathbf{c}}$ & $8.06 \pm 0.11^{\mathbf{b}}$ \\
\hline IV & $0.40 \pm 0.02^{\mathbf{a}}$ & $50.94 \pm 4.40^{\mathbf{a}}$ & $3.69 \pm 0.25^{\mathbf{a}}$ & $7.55 \pm 0.18^{\mathbf{b}}$ & $9.50 \pm 0.57^{\mathbf{a}}$ \\
\hline
\end{tabular}

The values are mean \pm S.E. Means with different superscript letter in the same column are significantly differ at $\mathrm{P}<0.05$. I; control group, II; aqueous ginger extract group, III; hyperlipidemic group, IV; hyperlipidemic pretreated group.

Table (5): Effect of aqueous extract of ginger on serum troponin-I, sodium and potassium levels and CK-MB enzymatic activity in hyperlipidemic rats

\begin{tabular}{|c|c|c|c|c|}
\hline Group & $\begin{array}{c}\mathrm{Na} \\
(\mathrm{mEq} / \mathrm{L})\end{array}$ & $\begin{array}{c}\mathrm{K} \\
(\mathrm{mEq} / \mathrm{L})\end{array}$ & $\begin{array}{c}\text { CK-MB } \\
(\mathrm{ng} / \mathrm{ml})\end{array}$ & $\begin{array}{c}\text { Troponin-I } \\
(\mathrm{ng} / \mathrm{ml})\end{array}$ \\
\hline I & $128.43 \pm 3.35^{\mathbf{a}}$ & $6.10 \pm 0.12^{\mathbf{a}}$ & $818.66 \pm 31.46^{\mathbf{b}}$ & $0.45 \pm 0.04^{\mathbf{c}}$ \\
\hline II & $128.20 \pm 5.35^{\mathbf{a}}$ & $3.67 \pm 0.15^{\mathbf{b}}$ & $649.53 \pm 38.54^{\mathbf{c}}$ & $0.04 \pm 0.01^{\mathbf{d}}$ \\
\hline III & $96.77 \pm 3.94^{\mathbf{b}}$ & $5.83 \pm 0.15^{\mathbf{a}}$ & $1007.01 \pm 82.58^{\mathbf{a}}$ & $1.73 \pm 0.05^{\mathbf{a}}$ \\
\hline IV & $95.57 \pm 2.87^{\mathbf{b}}$ & $4.27 \pm 0.09^{\mathbf{b}}$ & $712.57 \pm 26.90^{\mathbf{b c}}$ & $1.34 \pm 0.13^{\mathbf{b}}$ \\
\hline
\end{tabular}

The values are mean \pm S.E. Means with different superscript letter in the same column are significantly differ at $\mathrm{P}<0.05$. I; control group, II; aqueous ginger extract group, III; hyperlipidemic group, IV; hyperlipidemic pretreated group. 